\title{
"Los salvaguardias de aquellos seres mudos": notas sobre educación y formación de comunidades emocionales en el trato hacia los animales. Chile, c.1900-c.1930
}

\section{Pablo Toro-Blanco ${ }^{1}$}

Recibido: 23 de enero de 2018 - Aprobado: 10 de abril de 2019

\begin{abstract}
Resumen
El presente artículo explora sintéticamente las posibilidades de aplicar conceptos provenientes de la corriente de la historia de las emociones a la caracterización de un proceso de inducción a las y los estudiantes chilenos, durante el primer tercio del siglo XX, que pretendía que desarrollaran el buen trato y cuidado de los animales, para lo cual surgieron instancias socializadoras tanto escolares como extraescolares. Utilizando fuentes tales como publicaciones estudiantiles y revistas educacionales, se caracteriza el tipo de discurso elaborado para provocar un efecto emotivo que aseguraría la adhesión estudiantil al propósito señalado, dotado de componentes civilizatorios y moralizadores. Complementariamente, se destaca el componente transnacional involucrado en este movimiento formativo de la infancia escolarizada.
\end{abstract}

Palabras clave: educación chilena, régimen emocional, comunidad emocional, protección animal

* Este texto se deriva del desarrollo de dos proyectos de investigación a cargo del autor. Ellos fueron: Proyecto Fondecyt Regular 1140604 (2014-2017) y Proyecto de Fondo Interno de Investigación Universidad Alberto Hurtado (2014). Deseo agradecer la valiosa ayuda prestada en ellos por mis ayudantes Javiera Letelier Carvajal y Luis Felipe Caneo Meneses. También agradezco los comentarios realizados por los evaluadores anónimos del artículo.

1 Chileno. Doctor en Historia. Académico del Departamento de Historia, Facultad de Filosofía y Humanidades, Universidad Alberto Hurtado, Chile. E-mail: ptoro@uahurtado.cl 


\title{
"Protection for Those Who Cannot Speak": Notes on Education and Training of Emotional Communities in the Treatment Towards Animals, Chile c.1900-c.1930
}

\begin{abstract}
This article explores and synthesizes the possible application of concepts derived from the history of emotions to describe an induction process for Chilean students during the first third of the $20^{\text {th }}$ century aimed at teaching them the proper treatment and care for animals, and which is seen through both formal and informal education opportunities. Using sources such as student publications and educational journals, this text identifies the type of discourse generated to provoke an emotional effect that would ensure student adhesion to the cause in question, endowed with civilizing and moralizing components. Additionally, emphasis is placed on the transnational component involved in this formal children's education movement.
\end{abstract}

Keywords: Chilean education, emotional system, emotional community, animal protection

Desde finales del siglo XX, en cualquier sala de clases de algún país con medianos o altos ingresos, quienes ejercen la docencia se han visto desafiados a ocuparse de un número creciente de estímulos que han irrumpido en los territorios de la escolaridad de mano de acelerados avances tecnológicos. Teniendo como expresión prominente el acceso masificado por parte de niños y jóvenes a teléfonos celulares, fuente de tensión cotidiana entre su potencial disruptivo y las prácticas pedagógicas tradicionales, los elementos de la esfera digital también han implicado ocasionalmente retos a la economía emocional de lo escolar. Es muy probable que dispositivos virtuales y robóticos habrán de convertirse en habitantes más frecuentes de la vida cotidiana de la escuela como también de los hogares en el porvenir, compartiendo (o incluso desafiando) la relación tradicional entre los seres humanos y los animales no humanos. Ello puede suponer un reto también a la singularidad histórica de ese vínculo: un lazo en que los humanos han "utilizado" a los animales incluso para constituir su propia identidad. Así, mirado en perspectiva antropológica, "las explicaciones tradicionales de compañía entre animal y humano son típicas del modo «como si», basado en antropomorfizar a los animales: los seres humanos espontáneamente interpretan el comportamiento de los animales como si algunos animales fueran seres humanos" (De Gelder, 2016: 208). ${ }^{2}$ La expansión acelerada de una esfera ciber-mecánica introduce amplias interrogantes sobre el tipo de papel que lo no-humano desarrollará en la constitución de lo humano y de su identidad, así como también levanta interrogantes respecto al modo en

La traducción de la frase es nuestra. 
que los animales no humanos, partícipes tradicionales de la construcción de la índole de lo humano en diversas fases de su proceso filogenético, serán considerados en el futuro. Brinda, además, un pretexto plausible para plantearse algunas preguntas históricas sobre la intersección entre educación y emoción, propósito que anima a este texto, que se concentra en un dominio específico de esa relación: el establecimiento de discursos educacionales respecto al trato hacia los animales.

En estas páginas se pretende arrojar luz, de manera sumaria, sobre algunos aspectos de educación afectiva y emocional en el Chile de inicios del siglo XX, mediante la observación de cómo se manifestó la presencia de algunos discursos y prácticas organizativas que buscaban garantizar un comportamiento esperado de niñas y niños con los animales. Para ello se toma como marco de referencia al sistema escolar chileno de la época, así como también se alude a organizaciones benéficas, humanitarias y filantrópicas que se erigieron en cooperadoras de las funciones educacionales. En una época en que proliferaron instancias societarias que apelaban a la infancia, como ha documentado apropiadamente Jorge Rojas (2004), muchas de ellas incorporaron en su discurso humanitario y filantrópico el cuidado animal como una de sus divisas. Fue, por ejemplo, el caso de la Sociedad Protectora de Animales, fundada por el joven estudiante Jorge Meléndez Escobar (1896-1984), que será uno de los ejes de interés de estas páginas. ${ }^{3}$ Dicha organización, si bien no estaba dedicada exclusivamente a niñas y niños, sí consideró a la infancia, sin embargo, como un público destinatario

3 De acuerdo a lo que indica su perfil biográfico (recogido en el sitio web del Congreso Nacional de Chile del cual sintetizamos y transcribimos algunos párrafos para ilustrar el perfil de su personalidad profesional y vocación por actividades benéficas, filantrópicas y humanitarias), Meléndez nació en Santiago el 6 de marzo de 1896. Estudió en el Liceo de Aplicación y se tituló en el Instituto Superior de Comercio. Realizó cursos de Economía Política y Publicidad en la Universidad de Chile. Desde 1914 a 1916, fue profesor en las Escuelas Nocturnas para Obreros "Manuel Rodríguez" y en el Liceo de Aplicación. Se desempeñó en la Caja Nacional de Ahorros, llegando a ser su Jefe del Departamento de Prensa y Propaganda (1915-1949). Desarrolló variadas labores periodísticas. Militó en el Partido Independiente. Fundador del Movimiento Independiente y de la Acción Renovadora de Chile en 1949. Fue elegido diputado por Santiago (1949-1953, 1953-1957). Entre una amplia gama de actividades ejecutivas en instancias societarias, se destaca que fue presidente y fundador del Bando de Piedad de Chile (1919-1950), y de la Casa del Estudiante Americano desde 1950 en adelante. Presidente honorario de la Sociedad Protectora de Animales "Benjamín Vicuña Mackenna" (1916-1978). Consejero honorario de la Sociedad de Instrucción Primaria desde 1923 en adelante. Además formó parte de numerosas asociaciones y mutuales. Jorge Meléndez escribió Educación de la Juventud. Protección de los animales (1919); Ahorro y caridad (1932); Siembra y cosecharás amor (1981). Además, fue distinguido por su trabajo La cartilla del ahorro, en la Primera Conferencia del Ahorro celebrada en 1915. Por todas sus actividades recibió numerosos reconocimientos públicos y homenajes. Falleció en Santiago en marzo de 1984. Ver https://www.bcn.cl/historiapolitica/resenas_parlamentarias/wiki/ Jorge_Meléndez_Escobar, revisado el 8-IV-2019. 
preferencial, como es posible notar en sus publicaciones y discursos. Casos semejantes constituyeron la Liga de Bondad y el Bando de Piedad, sociedades coetáneas en las que el mismo Meléndez también tuvo participación y que intentaron conducir y modelar la filantropía de sectores estudiantiles acomodados y medios, introduciendo como uno de sus contenidos el deber de cuidado a la naturaleza y a los animales.

La elección del periodo se fundamenta debido a que comprende una etapa en la que se aprecia el surgimiento de un amplio conjunto de iniciativas destinadas a complementar las funciones formativas de la escuela, entre las que se cuenta las que hemos señalado en el párrafo anterior. Sin el propósito de someter la realidad en estudio al imperio de férreos modelos interpretativos, la idea (de reminiscencias foucaltianas) de una "ortopedia moral" podría resultar, sin embargo, una metáfora afortunada para hacer referencia a estas organizaciones que proliferaron en las primeras décadas del siglo XX acompañando los esfuerzos desplegados por escuelas y liceos. Como ha señalado el historiador Jorge Rojas, los primeros años del siglo XX fueron una coyuntura en la que se esparció una sensación colectiva de crisis, agudizada por los severos conflictos sociales existentes en el Chile de entonces, caracterizados tradicionalmente con el rótulo de "cuestión social". Si bien usualmente se ha reparado en las consecuencias que tales fenómenos implicaron para las masas populares consideradas en su conjunto y principalmente como masa trabajadora precarizada, también cabe preguntarse por el efecto "degenerador" (usando términos de la época) que significaban dichas penurias para la formación afectiva y emocional de niñas y niños. Era en ese marco que diversos sectores políticos, enfocándose en los riesgos de la pérdida de una supuesta cohesión sociocultural, "lamentaban la decadencia de los ideales patrios y proponían, como solución, acentuar la formación cívica de los niños, y así recuperar los antiguos valores, el perdido esplendor de la Patria" (Rojas Flores, 2004: 364). En tal escenario nacionalizador, por una parte, y racionalizador en clave cosmopolita, por otra, es que se encuadran las iniciativas, propuestas y asociaciones que se analizan a continuación, las que estuvieron lejos, en todo caso, de identificar directamente los riesgos morales y formativos de la infancia y juventud con causas profundas de índole social como, por ejemplo, los activos conflictos de clase de la época en cuestión.

\section{Breves antecedentes generales respecto del trato a los animales y su dimensión emocional}

Es bien sabido que el antropocentrismo es uno de los fundamentos de la cultura occidental y, por ende, de los procesos educativos. Como señala una investigadora, en la "división naturaleza versus cultura, y en el supuesto límite 
entre humanidad y animalidad, es un topos en el pensamiento antropológico la relación entre naturaleza y cultura, los seres humanos y animales, conductas innatas y aprendidas, filogenia y ontogenia[...]", todos ellos vínculos establecidos desde lógicas binarias (Tonucci, 2011: 183). ${ }^{4}$ Estas oposiciones se han visto tradicionalmente reforzadas mediante la educación. Sin embargo, sus formulaciones y contenidos tienen, ciertamente, un sentido contingente a cada época en que se enmarcan. Así, en el caso de los vínculos emocionales entre humanos y animales, parte importante de sus vicisitudes han tenido que ver con variaciones conceptuales de la atribución hecha de parte de los humanos a los animales no humanos acerca de su capacidad o no de tener emociones. Habiéndose iniciado como un problema estrictamente propio del campo de la filosofía (en que la lejana distinción aristotélica estableció la diferencia al respecto entre hombres capaces de logos y bestias no racionales, la que dio base a una prolongada noción que reducía a éstas a la calidad de sentientes pero no capaces de emociones ni sentimientos), los cambios tanto en el campo cultural como científico a partir del siglo XVIII incorporaron nuevas nociones y actores a la discusión. La creciente distinción entre sensación (como mero fenómeno sensible) y emoción o sentimiento (como su procesamiento fugaz, diferenciado a su vez de la facultad cardinal humana de la razón) se fue afirmando en el pensamiento occidental desde entonces, transfiriendo cada vez mayor interés a los fenómenos emocionales. Por otra parte, la configuración de campos disciplinares tales como la fisiología y la psicología abonaron nuevas discusiones acerca de las emociones en los seres humanos, pero también levantaron cuestionamientos al binario sobre el que se sostenía el antropocentrismo, principalmente dado que ya no era el ámbito de la razón pura el criterio de partición entre humanos y animales no humanos. Así, es sintomático de este amplio campo de intereses que autores seminales para la configuración moderna del concepto de "emoción" como Charles Darwin, integraron en su foco de interés a unos y otros, como queda reflejado en el título de una de sus obras referentes al asunto, The Expression of Emotions in Man and Animals, publicada en 1872.

El propio foco científico del evolucionismo, representado en Darwin, ayudó a levantar nuevas preguntas acerca de las facultades de los animales no humanos y, entre ellas, a plantear si poseían la capacidad de rebasar los límites de la mera sensación como interfaz inmediata con el mundo. Términos como "instintos", "impulsos", "tendencias" y "emoción" comenzaron, en la parte final del siglo XIX, a ser releídos a la luz del pensamiento evolucionista, dando pábulo a una posibilidad de dotar de base científica a un creciente proceso de "emocionalización" respecto a los animales, que estaba en curso desde el siglo anterior (Eitler, 2014: 109). Dicho desarrollo

$4 \quad$ La traducción de la frase es nuestra. Destacado en el original. 
había obedecido a innovaciones derivadas de un nuevo humanitarismo, en el que la lectura ilustrada, romántica y secularizada de categorías tales como la simpatía articuló las bases para la filantropía moderna, el cosmopolitismo cultural y el universalismo moral, cuya expresión cúlmine fue la doctrina de los derechos humanos. Frente a la herencia de la compasión cristiana, dada por fuente divina, la simpatía moderna se entendía intrínseca al ser humano y podía ser compartida sin cortapisas religiosas, de clase, nación o género (Frevert, 2011: 168). Ello estuvo detrás de la formación de causas humanitarias como el abolicionismo, en el paso del siglo XVIII al XIX, y también en la base de la nueva consideración prestada a los animales. Como consecuencia de ello, ya en el siglo XIX, se expandió una oleada de activismo en torno al cuidado de los animales, como parte de la agenda política de algunos grupos de las sociedades civiles de países europeos que, muy prontamente, detectaron la necesidad de difundir el mensaje de cuidado a los animales sobre todo en las nuevas generaciones. Así, por ejemplo, en el caso de Alemania, el movimiento de protección a los animales contaba, hacia fines del siglo XIX, con cerca de 100.000 adherentes activos (Eitler, 2014: 111). Por su parte, en Inglaterra se había discutido el problema del maltrato animal desde décadas antes, lo que se manifestó primero en una organización creada en 1824 que, a partir de 1840, pasó a ser reconocida como The Royal Society for the Prevention of Cruelty to Animals (Fagan, 2015: pos.790).

\section{La protección a los animales como fenómeno transnacional}

El interés en la formación cívica y moral de la infancia y la juventud como soporte para la estabilidad política es, indudablemente, pertinente como problema historiográfico que refleja circulaciones transnacionales de ideas. En el contexto temporal que aborda este estudio, tiene relación tanto con una función reactiva como con una proyectiva. En el primer caso, se inscribe en las preocupaciones específicas de la época acerca de la posible decadencia de la población concebida como un conjunto nacional y/o racial, de la que se consideraba que su estabilidad emocional (supuesto del orden social) podía hallarse en riesgo si no se producían las inducciones necesarias a promover la expresión de determinadas emociones (reputadas como funcionales o positivas) y a constreñir la demostración de otras, que se asumía que eran lesivas a los códigos de socialización esperados, en un contexto en el que la noción orientadora de "urbanidad" mantenía un peso normativo significativo en el discurso dirigido hacia los menores de edad, dando continuidad a la adhesión a formas de conducta europeas, tal como se había manifestado en la enseñanza en nuestro país desde mediados del siglo XIX (Toro-Blanco, 2012). En el caso británico, por ejemplo, semejan- 
te tipo de miedos a la deriva afectiva de las nuevas generaciones había conducido, algunas décadas antes, a la promoción de instituciones que buscaron preservar la idea de una infancia y juventud acorde a los ideales que sustentaban a esa cultura y su visión imperial, como ha demostrado claramente la historiadora Stephanie Olsen (2014) refiriéndose en específico a la formación de la masculinidad juvenil.

Un elemento que participa en la configuración de un discurso educacional de buen trato a los animales en el caso chileno es su evidente articulación transnacional. Con ello aludimos a que es pertinente mirar el fenómeno a partir del lente analítico de una historia transnacional que se ocupa preferentemente de la movilidad, circulación y transferencias de ideas y bienes, rebasando la determinación formal de un mero sentido internacional o interestatal (como podría ser una mirada más convencional respecto de la diplomacia o el comercio exterior), y atendiendo al modo en que fuerzas externas penetran en las sociedades o contribuyen a configurarlas (Conrad, 2006: 44). Ello se manifestaría, por ejemplo, en el sentido de divisa sin fronteras que adquirió, en la época que concita nuestro interés, el movimiento de la Escuela Nueva. Así, desde una perspectiva de una historia transnacional de la educación, el discurso de buen trato a los animales podría ser inscrito al interior de un marco de circulación de ideas educacionales que suponían nuevas relaciones pedagógicas, una suerte de "nuevo pacto educativo" (Toro-Blanco, 2019). De la mano de múltiples fuentes (las pedagogías activas, democráticas, transformadoras, asociadas a autores diversos como John Dewey, María Montessori, Adolphe Ferriere o Célestin Freinet, entre otros), la metamorfosis paidocéntrica de las relaciones educativas, integrando un grado mayor de atención a la psicología infantil y juvenil, fue un espacio fecundo para revalorizar lo sensitivo y afectivo, así como las vinculaciones de las y los niños con la naturaleza y el mundo animal.

Como ya se indicó, el humanitarismo que se expandió con fuerza desde el siglo XVIII teniendo como soporte la noción universalista de simpatía recaló en las más distintas latitudes, en ciclos no siempre homogéneos temporal ni conceptualmente. En el campo específico de los movimientos a favor del cuidado y buen trato de los animales, se presentaron apropiaciones locales de sus valores. Fue, por ejemplo, el caso de Cuba. Así, en la isla se fundó en 1882 una Sociedad Protectora de Animales y Plantas, que tenía numerosas referencias internacionales, entre ellas las de las sociedades homónimas de Cádiz (1872) y Madrid (1878), en el marco de la pervivencia tardía de la relación colonial. Años más tarde, ya bajo el influjo norteamericano, se establecería una Sociedad Humanitaria, Protectora de los Niños y contra la Crueldad con los Animales, replicando el modelo de la American Human Association (Funes Monzote, 2013: 233). La consideración de la experiencia norteamericana, entre otros focos referenciales, también habría de estar 
presente en el caso de la conformación de los espacios asociativos que aparecieron en Chile con la intención de promover en la infancia el buen trato a los animales. Por ejemplo, es sintomático que una de las primeras alianzas que logró la Liga Protectora de Animales fue con la Asociación de Educación Nacional (AEN). Ésta era una organización destinada a la promoción de una amplia agenda educacional con tintes progresistas y nacionalistas, fundada en 1902, que encontraba su modelo como organismo de influencia en la discusión pública sobre educación en la National Education Association, fundada en 1857 en Estados Unidos. En tanto grupo de presión, la Asociación impulsó buena parte de la discusión que se vio coronada en 1920 con la aprobación de la Ley de Instrucción Primaria Obligatoria. Como parte de su tarea de promover una agenda progresista, nacionalista y humanitaria, la AEN brindó espacio, durante 1915, en algunas ediciones de su medio oficial (la Revista de Educación Nacional), a la Liga para que diera a conocer sus principios orientadores y sus actividades. Por otra parte, cabe mencionar que la AEN fue un centro de reconocida filiación y articulación con el horizonte de referencia pedagógica norteamericano, lo que quedó expresado en que varios de sus directivos o cercanos formaron parte de las primeras camadas de viajeros pedagógicos que fueron a formarse a Estados Unidos en las primeras décadas del siglo XX.

La dimensión transnacional del movimiento local en pro del buen trato a los animales era explicitada, además, por sus propios representantes, que se entendían como parte de una corriente global, en la que concebían que sus esfuerzos se hallaban articulados con otras sociedades que rebasaban las fronteras del Estado Nación. Así, por ejemplo, Meléndez Escobar un actor principal de las iniciativas de promoción del buen trato a los animales en Chile, valoraba la acción llevada a cabo por la Dicky Birdy Society, fundada en Manchester, Reino Unido, en 1876, identificándola como un ejemplo inspirador para nuestro país (Meléndez, 1919: 21). En el mismo sentido, cuando la Sociedad Protectora de Animales tuvo posibilidades de generar publicaciones, entre ellas figuró una traducción de un folleto de origen norteamericano, identificado explícitamente como "publicado por la Sociedad Americana de Educación Humanitaria. 180 Longwood Avenue, Boston, Massachussetts. Dr. Francisco H. Rowley. Presidente; Guy Richardson, Secretario". No es claro, sin embargo, si la edición en cuestión fue hecha o no con fondos de esa misma organización extranjera, que ya vimos que había servido de referencia en el giro que hermanó cuidado animal y educación en el caso cubano a inicios de siglo. En este mismo rumbo global, un periódico estudiantil comprometido con la causa de la defensa de los animales informaba en 1922 sobre el estrechamiento de contactos con la Sociedad Peruana de Protección de Animales. Esta identificación afectiva con semejantes en la causa y el espíritu pero lejanos en el espacio puede entenderse, siguiendo los planteamientos de Jobs y Pomfret (2015: 11), como parte de una primera forma de articula- 
ción de redes transnacionales infantiles y juveniles en el siglo $X X$, en la que, ante la imposibilidad del viaje físico, serían los símbolos, gestos, uniformes, causas y códigos compartidos los que permitirían a menores de distintos países sentirse unidos por un motivo común.

La creación de la Sociedad Protectora de Animales en Chile también tiene otra faceta que es posible leer desde una óptica transnacional: tal como en otros países, también formó parte de una miríada de instituciones que buscaron, como se señalaba párrafos atrás, dotar a la sociedad de una suerte de "ortopedia moral", que pudiera acompañar los esfuerzos normalizadores que se desplegaban en el sistema escolar, los que eran limitados debido a las dificultades para lograr atraer y retener en las aulas a la infancia en edad escolar. Otras tantas formas de asociación humanitaria, benéfica o filantrópica también concurrieron a la tarea de promover, entre sus múltiples objetivos, el buen trato hacia los animales. Así, por ejemplo, sucedió con la Liga de Bondad, entidad que era dada a conocer a través de la Revista de la AEN en 1915. Se la presentaba como "una Sociedad de carácter eminentemente educativo, colaboradora de la escuela en el sentido de forjar caracteres" y que tiene por "objeto desarrollar en el niño la belleza moral, sin distinción de sexos, clases sociales, nacionalidad ni religión". Tiende esta liga a desarrollar en los jóvenes educandos el altruismo, los sentimientos puros de caridad, de ayuda a los débiles y de amor a los animales y plantas" (Revista de Educación Nacional, 1915: 209). Se destacaba que se podía participar de la Liga a partir de la temprana edad de siete años y que pertenecer a ella no tenía costo alguno. Es interesante apreciar que, en tanto mecanismo de socialización, la Liga pretendía incidir desde edades bastante tempranas en la infancia, lo que probablemente se explique por su apuesta a potenciar el impacto formativo de su mensaje y, por otra parte, para alcanzar a llegar al mayor número de niñas y niños en la escuela, dado que las tasas de deserción escolar eran altas y ello implicaba que, conforme se apuntara a edades mayores, sería más difícil contar con el apoyo de la escuela para el buen funcionamiento de la Liga. Por otra parte, el componente emocional y afectivo de los propósitos de la institución era explícito, en tanto se concebía como espacio de promoción de sentimientos determinados.

Cabe señalar que tanto la Sociedad Protectora como la Liga no eran instituciones educacionales propiamente tales ni se insertaban de modo oficial en escuelas y liceos. Concurrían a la configuración de un espacio formativo y de promoción de regímenes emocionales junto con otras organizaciones filantrópicas semejantes como el Bando de Piedad (en cuya fundación en 1919 participó el mismo Jorge Meléndez), sociedad que asimismo enfatizaba el deber infantil de respetar y cuidar a los animales y que también se reconocía como parte de un movimiento de amplitud internacional. Pese a 
ser estructuras extraescolares, era muy claro que estas sociedades buscaban acercarse a escuelas y liceos para difundir su mensaje, lo que quedaba de manifiesto en su capacidad de integrar como socios a cerca de 2.000 escolares de distintos colegios de Santiago, como se destacaba en una crónica sobre las actividades del Bando publicada en un semanario dedicado al público infantil (El Pibe, 1923: 17). Del mismo modo, también exploraron diversas formas de validación de parte de actores educacionales reconocidos y de las autoridades políticas. El caso de Jorge Meléndez sintetiza este tipo de estrategia de desarrollo de estas sociedades. Meléndez desarrolló un singular activismo en pos de promover la protección de los animales. Nacido en Santiago en 1896, estudió en el Liceo de Aplicación, en el cual participó en el giro que experimentó La Tribuna Estudiantil, originalmente una publicación oficial de los estudiantes de ese establecimiento, que en 1915 incorporó a su nombre el texto "Dirigida por el Secretario de la Sociedad Protectora de Animales 'Benjamín Vicuña Mackenna'" y luego, lisa y llanamente, pasó a ser el órgano oficial de la Sociedad Protectora, dejando fuera de su encabezado la referencia al Liceo de Aplicación. El cambio del periódico estudiantil llevado a cabo por Meléndez generó un medio de comunicación que, de acuerdo a lo que declaraba la propia publicación, tenía un tiraje bastante amplio (cinco mil ejemplares, cifra que habría que tomar con recaudo) y era distribuido en forma gratuita.

El energético estudiante Meléndez complementó la proyección hacia los estudiantes con una búsqueda de reconocimiento al valor educacional de su causa. Sus esfuerzos tuvieron una primera recompensa cuando, mediante decreto del Ministerio de Instrucción Pública, fechado en 15 de diciembre de 1917, se estableció que su obra Educación de la Juventud. Protección a los animales sería considerada como texto auxiliar para el uso de las escuelas primarias. Además, la edición del libro del joven autor fue costeada con fondos públicos tras un informe positivo enviado a las autoridades por Darío Salas, en abril de 1919. En su evaluación Salas, figura pública de la discusión educacional, con estudios de posgrado en los Estados Unidos y frecuente colaborador de la AEN, sostenía que el texto y sus imágenes constituían un conjunto "perfectamente apropiado para hablar a la mente y el corazón infantiles, [y] serán para el niño un objeto de constante interés y una fuente inspiradora de los mejores sentimientos y de las más favorables actitudes hacia los compañeros y colaboradores del hombre" (Meléndez, 1919: 4). Años después, la Sociedad sería reconocida como una institución "cooperadora de la función educacional del Estado", en 1928, mediante el decreto supremo 2159 (Sociedad Protectora, 1944: 2), coronando la estrategia de su fundador de situarla en un escenario de cercanía a fuentes de legitimidad y apoyo que le permitieran contar con algún grado de apoyo estatal y llegada efectiva al aparato escolar, tanto estatal como receptor de financiamiento público mediante aportes y subvenciones. Testimonio de esto 
último sería, por ejemplo, la realización de la Primera Semana Escolar de Protección a los Animales, llevada a cabo en octubre de 1928 en la Escuela Francisco Arriarán, establecimiento educacional que era mantenido por la Sociedad de Instrucción Primaria en Santiago (Sociedad Protectora, 1928: 6). Al año siguiente se reportaba que se había llevado a cabo la Semana de la Naturaleza o del Amor y Cariño a los Animales, actividad que tuvo lugar en varias escuelas públicas tanto de Santiago como de otras ciudades del país (Vida Nueva, 1929: 3).

La generación de este espacio societario ligado a causas humanitarias se sostuvo durante los años siguientes, dando lugar a menciones cruzadas entre instituciones que, en lo medular, diferían en su objeto pero que tenían siempre a la vista su potencial de mayor impacto si dirigían su mensaje a la infancia y juventud y para ello buscaban asociarse con escuelas y liceos y complementar su acción. Así, por ejemplo, en el periódico Vida Nueva, Boletín de la Liga Nacional contra el Alcoholismo, comenzaron a aparecer en 1929 menciones frecuentes al Bando de Piedad e informes sobre las actividades de la Sociedad Protectora de Animales Benjamín Vicuña Mackenna (Vida Nueva, 1929: 3). En suma, organizaciones humanitarias y filantrópicas lograron converger en un espacio caracterizado y potenciado por cruces de individuos participantes en ellas y se insertaron en una coyuntura en que otras formas (también con elementos transnacionales) dirigidas a la infancia y juventud prosperarían gracias a las preocupaciones adultas respecto del uso apropiado del tiempo libre de niñas y niños, lo que quedó reflejado en la explosiva expansión que vivió, desde 1909, el movimiento de los Boy Scouts, estudiado consistentemente por Jorge Rojas Flores, que también tenía inserto en sus mandatos el cuidado y respeto a los animales (Rojas, 2006: 70). Este amplio horizonte de formas de asociación puede ser interpretado como una convergencia de orientaciones afectivas y emocionales, ciertamente no del todo homogéneo pero sí con muchos puntos en común en sus propósitos de normalización de la infancia y juventud. A continuación se presentan brevemente algunas de estas dimensiones en el caso específico de la promoción del buen trato a los animales.

\section{La generación de un régimen emocional de buen trato a los animales}

Tras la preocupación por promover mediante la educación y la socialización infantil y juvenil en el tiempo libre un nuevo trato a los animales estaba en juego la construcción de determinadas reglas emocionales, proceso que podría ser entendido tanto en los términos propuestos por Reddy (2001), al referirse al concepto de "régimen emocional" o de acuerdo a la conceptualización desarrollada anteriormente por Stearns (1985) y rotulada como 
"emocionología". ${ }^{5}$ Ambas nociones aluden, en suma, a formas de manejo emocional entre actores en situación de asimetría, lo que se hace evidente al considerar que el problema a tratar acá tiene que ver con relaciones entre adultos y niñas y niños en edad escolar. Para que dichas formas de regimentación afectiva pudieran tener la mayor eficacia posible, debían emplear medios y lenguajes que pudieran interpelar en profundidad a su público destinatario. Ello se expresó en utilizar un recurso a hacer semejantes discursivamente a animales y hombres, antropomorfizándolos: un "como si", que fue uno de los dos dispositivos discursivos más relevantes encontrado en folletos de la sociedad y publicaciones dedicadas a la infancia. A través de imágenes de animales interactuando con los niños y de textos supuestamente escritos por animales, como caballos o perros, se entregaron mensajes morales y humanitarios. Curiosamente, esos mensajes eran un crisol de diferentes fuentes, de las que no estaba ajena la cultura católica prevaleciente en el país en la época, lo que se podía apreciar en las formas catequísticas empleadas o en alusiones bíblicas como, por ejemplo, al final de la difundida Oración de un Caballo: "durante el trabajo háblame; tu voz es para mí más eficaz que las riendas y la fusta. Acaríciame y enséñame a trabajar con buena voluntad (...) Mientras vivo trátame con la consideración debida a un criado fiel y útil. Si no te entiendo inmediatamente no te desesperes y me castigues, es fácil que no sea culpa mía (...) Perdona haber ocupado tu atención con ésta, mi humilde plegaria, que te ruego no olvides, y que te la hago respetuosamente, invocando a aquel que nació en un pesebre" (Meléndez, 1919:5).

Complementariamente, un segundo dispositivo para entregar el discurso de protección de los animales tomaba cuerpo a través de medios textuales más tradicionales y cercanos a la lógica de lo escolar: mediante breves aforismos, generalmente sin imágenes que pudieran distraer el foco de interés del mensaje. Un perfil moral posiblemente de fundamentos laicos se apreciaba a través de frases como estas, frecuentes en las publicaciones de la Sociedad Protectora:

"Comprender el dolor de todo ser viviente es característica de los pueblos civilizados".

Las definiciones originales respectivas de los conceptos son: a) régimen emocional: "The set of normative emotions and the official rituals, practices, and emotives that express and inculcate them; a necessary underpinning of any stable political regime" (Reddy, 2001: 129). b) emocionología: "The attitudes or standards hat a society, or a definable group within a society, maintains toward basic emotions and their appropriate expression; ways that institutions reflect and encourage these attitudes in human conduct, e.g., courtship practices as expressing the valuation of affect in marriage, or personnel workshops as reflecting he valuation of anger in job relationships" (Stearns, 1985: 813). 
"Si maltratas un animal cometes una injusticia y endureces tu corazón".

"La dulzura del hombre en su trato con los animales es la primera manifestación de superioridad".

Además de los recursos de dotar de voz a los animales y formular aforismos, también es relevante considerar que las tonalidades textuales de los medios usados para la promoción del buen trato a los animales adquirían un sentido de invocación militante, propiciatorio para una apelación emocional. En esa clave debiera sr comprendido el manifiesto lanzado en las páginas de Tribuna Estudiantil por el joven Meléndez:

"Aquí estamos! Los protectores de los animales.

Firmes en nuestro puesto de lucha, con el ardor que las buenas causas engendran en los corazones nobles y patriotas.

Aquí estamos, para combatir, sin tregua, a aquellos que desconociendo los sufrimientos de los seres irracionales, les maltratan sin piedad. Iremos caminando con paso firme, hacia nuestro codiciado ideal, sin escuchar a los rezongones, egoístas e indiferentes y llevando muy en alto el pabellón de "la Justicia y de la Piedad" (...)

Para bien de la Patria, ya tenemos una nueva juventud, que se está formando en la gran Escuela de la Justicia. Los centenares de adherentes a la Sociedad Estudiantil Protectora de Animales se han constituido los salvaguardias de aquellos seres mudos que sufren en silencio las inclemencias del destino. A ellos nada les detendrá, porque se sienten poseídos de la fuerza que da el convencimiento de una causa noble y justa.

¡Aquí estamos!" (La Tribuna Estudiantil, 1921: 1).

Ardor, firmeza, fuerza se estructuraban en una cadena semántica que llamaba a una disposición activa en pos del objetivo común. Haciendo eco de las concepciones en vigencia en la época respecto a un rol de la juventud como misionera, dotada de un halo de mesianismo, la exhortación del joven activista dibujaba además las fronteras de quienes estaban dentro y fuera del espacio afectivo en cuestión: frente a los "rezongones, egoístas e indiferentes" se alzaban los "poseídos de la fuerza" de la buena causa. Esta noción de un "estar adentro" de un orden afectivo determinado también se hacía presente en otras sociedades humanitarias dirigidas a niños y jóvenes. A mediados de 1922, el medio de la Sociedad Protectora reproducía los estatutos del Bando de Piedad de Chile, entidad existente desde agosto de 1919, que proclamaba en la leyenda de su sello institucional como sus valores orientadores "Amor, Justicia y Caridad". Llama la atención un par de artículos: 
"10. La justicia para los débiles, la indiferencia para los que nos mortifican y calumnian y el amor para todos, son las armas del Bando de Piedad de Chile, con que se deben vencer las dificultades, los disgustos, las mortificaciones, las burlas y las humillaciones que forman el ejército del enemigo.

11. Queda estrictamente prohibido tomar en broma los asuntos tratados en el Bando de Piedad, del mismo modo merecerán amonestaciones o castigos los socios que se valgan de chismes o medidas poco correctas para desprestigiar a la institución".

Al considerar lo propuesto por el reglamento de la Liga, puede apreciarse nuevamente el trazado de un sentido comunitario, en que se contrasta las creencias compartidas (cuya seriedad amerita no poder someterlas a duda o al escarnio de la broma o la ironía) en el combate contra la mortificación, la calumnia, las burlas y humillaciones provenientes del "ejército del enemigo". Así, buscando galvanizar una afectividad común, el modelo propuesto por la Liga suponía lo que podríamos considerar como una suerte de "consenso activo" de parte de las y los estudiantes que se integraran a ella. No era un espacio formativo en el sentido tradicional de transmisión de valores mediante lecciones, sino que involucraba un compromiso de llevar adelante el ideario mediante conductas concretas y que involucraban a niños y jóvenes de modo personal. De tal modo, se establecía que sus integrantes "deberán comprometerse a realizar, a lo menos, un bien chico o grande por día, prestar servicio a los ancianos, enfermos, inválidos, indigentes, a los niños menores que ellos, a sus propios compañeros y también proteger a los animales y a las plantas" (La Tribuna Estudiantil, 1922: 21). Además, la adhesión a los valores de la Liga debía ser manifestada de modo público, visible y cotidiano, mediante una insignia, que cada integrante debía portar, con la frase: "Yo sirvo". Es interesante considerar que dicho distintivo podría ser interpretado como la materialización simbólica, usando como soporte al cuerpo, de una disposición emocional de adhesión a un régimen afectivo, teniendo como matiz no menor el hecho de que tal comunión formaba parte de un acto voluntario, lo que podría poner algún grado de duda sobre la pertinencia de las categorías enfocadas principalmente en lo regimentado de las vinculaciones afectivas, o sea, las nociones de régimen emocional y emocionología a las que se ha hecho alusión párrafos atrás.

Desde una perspectiva de historia de las emociones y afectos, los elementos de adhesión activa y voluntaria recién señalados resultan interesantes como símbolos de pertenencia, a nivel declarativo, a lo que se podría asimilar con una "comunidad emocional", usando los términos propuestos por Bárbara Rosenwein (2010). Por ende, parafraseando lo indicado en la definición de la investigadora norteamericana, los niños y jóvenes pertenecientes a la Liga podrían haber experimentado la integración en un cuerpo colectivo en el 
que se definían como valiosos un determinado tipo de valores y emociones, del mismo modo que en ese espacio emocional se permitía y fomentaba la expresión de éstas y se asumía que otras debían ser desterradas de sus conductas cotidianas. Al participar de dichas comunidades emocionales, niños y jóvenes pertenecientes a las sociabilidades humanitarias trazaban límites de reconocimiento de su identidad como partícipes de la adhesión a un mismo horizonte afectivo compartido, el que aspiraban a llevar a su expansión mediante una actitud proselitista. Por extensión, quienes integraban la Liga o la Sociedad Protectora se hermanaban con un horizonte afectivo que, como se ha señalado, tenía alcance transnacional. Por ende, sociabilidades como la Liga o la Sociedad Protectora de Animales jugaban un papel de intermediarios entre constelaciones globales de disposiciones afectivas reputadas como positivas y la experiencia local, que podía hermanar en la distancia a los cientos de integrantes de la Liga de Bondad en Chile con los más de siete millones de integrantes que tenía su correspondiente en los Estados Unidos, de acuerdo al reporte (probablemente hiperbólico) que se indicaba en las publicaciones de dicho organismo humanitario.

La causa de protección a los animales mantuvo capacidad para concitar adhesión durante el periodo en estudio. Hacia 1929 se daba a conocer que en más de setecientas escuelas a lo largo del país se habían establecido "Sociedades Infantiles de Protección a los Irracionales". Independientemente del hecho de que esas sociedades formaran o no parte orgánica de la Sociedad Protectora de Animales y de su duración y organización, un indicador interesante de la persistencia de los elementos propios de una comunidad emocional formalizada se hacían ver en el requisito de inicio que se pedía para pertenecer a ellas, que consistía en suscribir la siguiente promesa: "Haré todo lo posible por tratar a todo ser viviente con benevolencia y hare esfuerzos para protegerlos de todo mal tratamiento". Un lenguaje común en que se iteraban términos como conmiseración, nobleza, dulzura de sentimientos, moral, entre otros estaba disponible para movilizar afectivamente a quienes fueran expuestos a él y voluntariamente decidieran conmoverse. Beatriz Contreras, una niña de trece años, alumna de quinto año de la Escuela Superior $n^{\circ} 27$ en Santiago, se encontró entre ellos. Valorando la obra benéfica de la Sociedad Protectora, transida emocionalmente por la tristeza, Beatriz se preguntaba "¿por qué habrá personas tan crueles, tan sin caridad para con los animales?" (Vida Nueva, 1929: 3).

\section{Reflexiones finales}

A partir de lo visto sucintamente en estas páginas, es posible identificar algunos elementos que pueden resultar de utilidad para caracterizar, a través del estudio del discurso promovido por sociedades humanitarias dirigidas a la 
infancia y la juventud de inicios del siglo XX, la estructuración de un régimen emocional que, al alentar en niñas y niños determinadas actitudes hacia los animales, pretendió constituirse en un patrón normativo funcional al orden, la urbanidad, los valores de una deseada ciudadanía cosmopolita y global. Siendo parte de un movimiento intelectual, filosófico y científico de mayor proyección temporal, que hundía sus raíces en las nuevas conceptualizaciones sobre las emociones surgidas sobre todo a partir del siglo XVIII (expresadas en un nuevo humanitarismo de proyección global), el movimiento a favor de un nuevo y mejor trato a los animales puede ser inscrito, tanto en una escala local como global, como parte de un proceso de construcción de discursos emocionales tendientes al control y manejo de la violencia. Cabe hacer notar que la socialización de tales discursos cobraba importancia estratégica para la cohesión de la sociedad, sobre todo considerando que en la época que se aborda en estas páginas se estaba experimentando un tránsito conceptual en el análisis social, comenzando a ser más bien periféricas (aunque no totalmente impopulares todavía) las nociones deterministas basadas en el marco de las diferencias implícitas de civilizaciones por razones biológicas (darwinismo social en la visión de Herbert Spencer, determinismo racial al estilo de Gustave Le Bon), en beneficio de explicaciones sociológicas. En éstas predominaba el interés por las condiciones específicas que permiten la cohesión de una sociedad y (lo que es importante para nuestro asunto) se relevaba entre ellas a las dimensiones afectivas y emocionales. Así, para un fundador de la sociología moderna como Emile Durkheim la pertenencia y la integración a una sociedad eran, entre otros factores, producto de filiaciones afectivas. Por ende, formas educativas deberían enfrentar, mediante la creación de un "carácter social", el individualismo rampante producto de la modernización y así garantizar la filiación afectiva que daría viabilidad al orden social (Saada, 2015: 70-71). En ese marco general es que cobra sentido la experiencia de las sociedades humanitarias que se han mencionado en el curso de este texto.

Para lograr modelar la filiación afectiva funcional a la cohesión de la sociedad en infancia y juventud la promoción del humanitarismo resultó, por ende, un campo necesario de explorar. A través de herramientas retóricas como la humanización de los animales, concediéndoles voz "como si" fueran humanos en textos y narraciones, se buscó despertar en las y los estudiantes las potencialidades aglutinadoras de la simpatía, entendida como disposición favorable a la consideración respetuosa del otro (en este caso, el animal no humano) y, por ende, a la afirmación de la necesidad de la continencia y dominio sobre las emociones disfuncionales a lo urbano y lo político, pasiones castigadas en el discurso y en la norma y que podían derivar, por su extensión en el trato entre seres humanos, en una continuidad de prácticas violentas. Tras la promoción del trato humanitario a los animales se escondía, con mayor o menor sentido explícito, la preocupación por el control de los 
propios "instintos animales" subyacentes en el carácter de niños y jóvenes (que estaban siendo explorados y caracterizados con índices científicos por la psicología en la época) y el potencial desestabilizador, disruptivo y eventualmente criminal que podía encontrarse inscrito en el aprendizaje temprano del maltrato a otros seres vivos. Ello se hacía visible, en ocasiones, en aforismos que las publicaciones de las sociedades humanitarias pro cuidado de los animales destacaban. Así, por ejemplo, quedaba de manifiesto en la sentencia (atribuida a Michelet) que una revista estudiantil planteaba a sus lectores en 1922: "Ios niños que son crueles con los animales desde la infancia, empiezan por matar a un pájaro y concluyen por asesinar a un hombre" (Tribuna Estudiantil, 1922: 2).

En los propósitos declarados por entidades que formaban parte de aquella suerte de "ortopedia moral" que acompañó los esfuerzos de la educación institucionalizada en las primeras décadas del siglo XX en Chile puede apreciarse un esfuerzo por establecer tempranas instancias de creación de lazos afectivos, bajo la forma de comunidades emocionales en las que se modelaban comportamientos que cumplían el rol tanto de entregar identidad grupal como también de establecer capacidades para interpelar tanto a pares como a adultos en pos de la causa moral defendida (ya fuera el buen trato a los animales, la defensa de la naturaleza, la promoción del respeto a los ancianos o la lucha contra el alcoholismo). Gracias a estudios enfocados en la socialización temprana de la infancia chilena en el siglo XX, expresados en las investigaciones ya referenciadas de Jorge Rojas Flores (2004 y 2006) parte importante de este horizonte temático ha sido iluminado. Queda, de todos modos, abierto para futuras investigaciones profundizar en las dimensiones afectivas asociadas a la experiencia de niñas y niños en estas comunidades emocionales y a su capacidad de agencia al interior de ellas.

\section{Referencias bibliográficas}

\section{Fuentes primarias}

a) Periódicos y revistas

El Pibe. Revista Semanal Ilustrada. Santiago, Año I, №1, 1923.

La Tribuna Estudiantil. Revista mensual. Dirigida por el Secretario de la Sociedad Protectora de Animales "Benjamín Vicuña Mackenna". Órgano oficial de los alumnos del Liceo de Aplicación. Santiago, 1921.

Revista de Educación Nacional. Santiago. Año X, №4, junio 1915.

Vida Nueva. Boletín mensual de la Liga Nacional contra el Alcoholismo. Año V, 1929. 


\section{Fuentes secundarias}

a) Artículos y capítulos de libros.

Eitler, P. (2014). "The 'Origin' of Emotions: Sensitive Humans, Sensitive Animals", en U. Frevert et al., Emotional Lexicons Continuity and Change in the Vocabulary of Feeling 1700-2000. Oxford: Oxford University Press, pp. 91-117.

Funes Monzote, R. (2013). "Animal Labor and Protection in Cuba: Changes in Relationships with Animals in the Nineteenth Century", en M. Few y Z. Tortorici (Editores), Centering animals in Latin American history. Durham: Duke Univesity Press, pp. 209-242.

Jobs, R. y Pomfret, D. (2015). "The Transnationality of Youth", en R. Jobs y D. Pomfret, (Editores), Transnational Histories of Youth in the Twentieth Century. New York: Palgrave MacMillan, pp. 1-19.

Rosenwein, B. (2010). "Problems and Methods in the History of Emotions", en Passions in Context, Vol. I, No1, pp. 1-32.

Saada, E. (2015). "France: sociability in the Imperial Republic", en M. Pernau et al., Civilizing emotions. Concepts in Nineteenth-Century Asia and Europe. Oxford: Oxford University Press, pp. 63-82.

Stearns, P. y C. Stearns (1985). "Emotionology: Clarifying the History of Emotions and Emotional Standards", en The American Historical Review, Vol. 90, №4, pp. 813-836.

Tonutti, S. (2011). "Anthropocentrism and the definition of 'culture' as a marker of the human/animal divide", en R. Boddice (Editor), Anthropocentrism: human, animals, environments. Leiden: Brill, pp. 183-199.

Toro-Blanco, P. (2012). "Dimensiones de la confección de una juventud virtuosa: manuales de urbanidad en Chile (c.1840-c.1900)", en Universum, Vol. 27, №1, pp. 191-205.

Toro-Blanco, P. (2019). "Conselhos de viajantes: a Escola Nova e a transformação do papel do professor no Chile (1920-1930). Um olhar conciso da história transnacional e das emoções", en D. Vidal y R. Silva Rabelo (Compiladoras) Movimento Internacional da Educação Nova. Sao Paulo: Fino Traço Editora [en prensa]

\section{b) Libros}

Conrad, S. (2006). What is Global History? Princeton: Princeton University Press. de Gelder, B. (2016). Emotions and the Body. New York: Oxford University Press. Educación Humanitaria. Como debemos cuidar a los animales (1928). Concepción: Imprenta y Litografía Westcott y Co. 
Fagan, B. (2014). The Intimate Bond. How Animals shaped Human History. Londres: Bloomsbury Press. [e-book]

Frevert, U. (2011). Emotions in history: lost and found. Budapest: Central European University Press.

Meléndez, J. (1919). Educación de la juventud. Protección a los animales. Santiago: Imprenta, Encuadernación y Litografía Selecta.

Meléndez, J. (1932). Ahorro y caridad. Santiago: Imprenta Universitaria.

Meléndez, J. (1981). Siembra y cosecharás amor. Santiago: Imprenta Barcelona.

Olsen, S. (2014). Juvenile Nation. Youth, emotions and the Making of the Modern British Citizen, 1880-1914. Londres: Bloomsbury.

Reddy, W. (2001). The navigation of feelings. A framework for the history of emotions. Cambridge: Cambridge University Press.

Rojas Flores, J. (2004). Moral y prácticas cívicas en los niños chilenos, 1880-1950. Santiago: Ediciones Ariadna.

Rojas Flores, J. (2006). Los Boy Scouts en Chile, 1909-1953. Santiago: DIBAM.

Sociedad Protectora de Animales Benjamín Vicuña Mackenna (s/f). Memoria de 1928. Santiago: s/i.

Sociedad Protectora de Animales Benjamín Vicuña Mackenna (1944). Cartilla de protección a los animales. Santiago: Imprenta y Litografía Universo. 